\title{
COPPERII-SELECTIVE ELECTRODES BASED ON 1-FUROYL-3,3-DIETHYLTHIOUREA AS A NEUTRAL CARRIER
}

\author{
M. DE LOS A. ARADA PÉREZ ${ }^{1 *}$, SANTIAGO LANDAZURY YANES ${ }^{1}$, M. CARDONA ${ }^{1}$, \\ L. AGUILERA ${ }^{I}$ M.YAZDANI-PEDRAM \\ ${ }^{1}$ Department of Analytical Chemistry, Eastern University of Cuba, Santiago de Cuba. \\ ${ }^{2}$ Polymer Laboratory, Faculty of Chemical and Pharmaceutical Sciences, University of Chile, Sergio Livingstone Pohlhammer 1007, \\ Independencia, Santiago, Chile. \\ (Received: January 20, 2010 - Accepted: July 14, 2010)
}

\begin{abstract}
1-furoyl-3,3-diethylthiourea was used as a novel neutral carrier in ion selective electrode for copper ${ }^{\text {II }}$ detection and determination. The $\mathrm{Cu}^{2+}$ selective plasticized polyvinyl chloride (PVC) membrane electrode exhibited reversible potential responses with Nernstian slope of $29.34 \pm 0.6 \mathrm{mV} / \mathrm{decade}$ for $\mathrm{Cu}^{2+}$ ions in the concentration range from $1.0 \times 10^{-7}$ to $1.0 \times 10^{-2} \mathrm{~mol} / \mathrm{dm}^{3}$ with a practical detection limit (PDL) of $3.84 \times 10^{-7}$ and lower limit of linear response (LLLR) of $6.15 \times 10^{-7} \mathrm{~mol} / \mathrm{dm}^{3}$ and a life-time of 20 days. The response time, $\mathrm{pH}$ effect and other characteristics of the electrodes were also studied.
\end{abstract}

Keywords: Neutral carrier; Copper ${ }^{\mathrm{II}}$-selective potentiometric sensor; Ion-selective electrode (ISE).

\section{INTRODUCTION}

Copper can be found in many kinds of food, in drinking water and in air. The absorption of copper is necessary, because copper is a trace element that is essential for human health. Although humans can handle proportionally large concentrations of copper, too much copper can still cause eminent health problems. However, copper deficiency causes anemia ${ }^{1}$. Environmental effects of copper occur when it ends up in soil. Copper strongly attaches to organic matter and minerals. As a result, it does not travel very far after release and it hardly ever enters groundwater. In surface water copper can travel great distances, either suspended on sludge particles or as free ions. Therefore, the presence of copper in the environment can affect the human and animal health and a fast efficient method of its determination is necessary.

Potentiometric measurements with copper ion selective electrode allow the direct determination of free $\mathrm{Cu}^{2+}$ ion concentration in aqueous samples. Ion-selective electrodes (ISEs) based on ionophores are widely used ${ }^{2-12}$ and plasticized polyvinyl chloride (PVC) membrane ISEs based on several kinds of neutral carriers, such as Schiff's bases ${ }^{2-11}$, calixazacrown ether ${ }^{3}$ as typical ionophore are convenient for determining ionic species in analytical chemistry and environmental monitoring.

The present study describes polymer membrane electrodes responsive to $\mathrm{Cu}^{2+}$ ions based on 1-furoyl-3,3-diethylthiourea as a new neutral carrier containing chelating sites.

\section{EXPERIMENTAL}

\section{Materials and methods}

The water used in this work was bidistilled water with a conductivity of less than $2 \mathrm{mS} / \mathrm{cm}^{-1}$. All the reagents used in this study were of analytical grade. Poly(vinylchloride) (PVC) from Fluka was used as polymeric matrix. The plasticizer used was dioctyl phthalate (DOP) from Riedel-de Haën and was employed as solvent mediator of the PVC liquid membrane. Tetrahydrofurane (THF) was analytical grade from Merck. The 1-furoil-3,3-dietiltiourea was synthesized in the laboratory of natural products of the University of Havana, Cuba. The epoxy conducting resin was prepared by mixing Araldite M and Hardener $\mathrm{H}$ form Ciba-Geigy and graphite powder from Merck as already described by Arada Pérez et.al. ${ }^{13-14}$ for nitrate sensors obtaining a resistance of $\leq 2 \mathrm{k} \Omega$.

A $\mathrm{pH} / \mathrm{mv}$ meter OAKLON digital $\mathrm{pH}$ meter with a precision of \pm 0.1 $\mathrm{mV}$ was used for measuring the potential difference between reference and indicator electrodes. The reference electrode used in this study was an $\mathrm{Ag} /$ $\mathrm{AgCl} \mathrm{HI} 5311$ double junction electrode and a solution of $0.1 \mathrm{~mol} / \mathrm{dm}^{3}$ of $\mathrm{K}_{2} \mathrm{SO}_{4}$ was employed in the external electrode compartment. A microprocessor Hanna $\mathrm{pH}$ meter model 213 was used for measuring the $\mathrm{pH}$ with a combined electrode with epoxy body Oaklon model WD-35881-00 and a hot plate-stirrer Jenway model 1000 LT.

\section{Preparation of the membranes}

The preparation of the electrode body and the application of the membrane were carried out in a similar manner as the method used for the construction of the all-solid-state ion selective electrodes reported in the literature ${ }^{13-14}$. The prepared membranes contained $6 \mathrm{Wt}$. \% of 1-furoyl-3,3-diethylthiourea as ionophore, $61 \mathrm{Wt}$. \% of dioctyl phthalate as plasticizer and $33 \mathrm{Wt}$. \% of PVC as the polymeric matrix.

Determination of the electromotive force (EMF)

The electromotive force (EMF) determinations were carried out by using a cell at $25 \pm 0.5^{\circ} \mathrm{C}$. The composition of the electrochemical cell was:

$\begin{array}{lll}\mathrm{Ag} / \mathrm{AgCl} / \mathrm{KCl} & 0.1 \mathrm{~mol} / \mathrm{dm}^{3} \mid \mathrm{K}_{2} \mathrm{SO}_{4} & 0.1 \mathrm{~mol} / \mathrm{dm}^{3}|| \text { test }\end{array}$ solution || $\mathbf{P V C m e m b}$.|cond. supp. $\mid \mathrm{Cu}$ (s)

The calibration curves were used to calculate such parameters as slope (S), practical detection limit (PDL) and Lower Limit of Linear Response (LLLR). This was done following the Nernst law through data adjustment by linear regression method. The calibration parameters were obtained by applying the method of additions ${ }^{15}$, determining the activity of the principal ion by using the Debye-Hückel equation (equation 1).

$$
\log f=0.51 Z^{2} I^{1 / 2} / 1+I^{1 / 2}
$$

The selectivity coefficients $\left(K_{B}^{\text {Pot }}\right)$ were determined by using the method of mixed solutions ${ }^{15}$ through the equation 2 .

$$
K_{A B}^{P o t}=\frac{a_{A}}{a_{B}{ }^{A / Z_{B}}}
$$

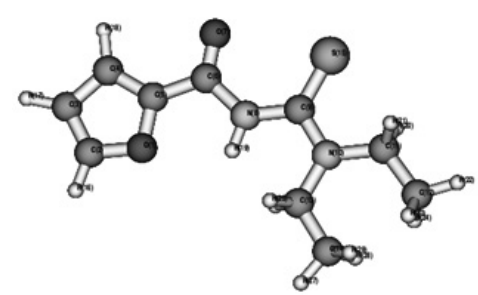

Figure 1: Structure of 1-furoil-3,3-diethylthiourea employed as ionofore. 


\section{RESULTS AND DISCUSSION}

The calibration parameters obtained from calibration curves of electrodes are shown in table 1. It is seen from this table that the constructed electrodes responded adequately to $\mathrm{Cu}^{2+}$ ions, the values for the slope (S) correspond to those expected by Nernst for a divalent anion. Figure 2 shows the calibration curve obtained for $\mathrm{Cu}^{2+}$ ions, evidenced the good linearity of the calibration curves for the plasticizer used as solvent mediator in this study. The calibration curve was checked repeatedly during 20 days, in the time of life of the electrode, for five replies of the electrode $(n=5)$.

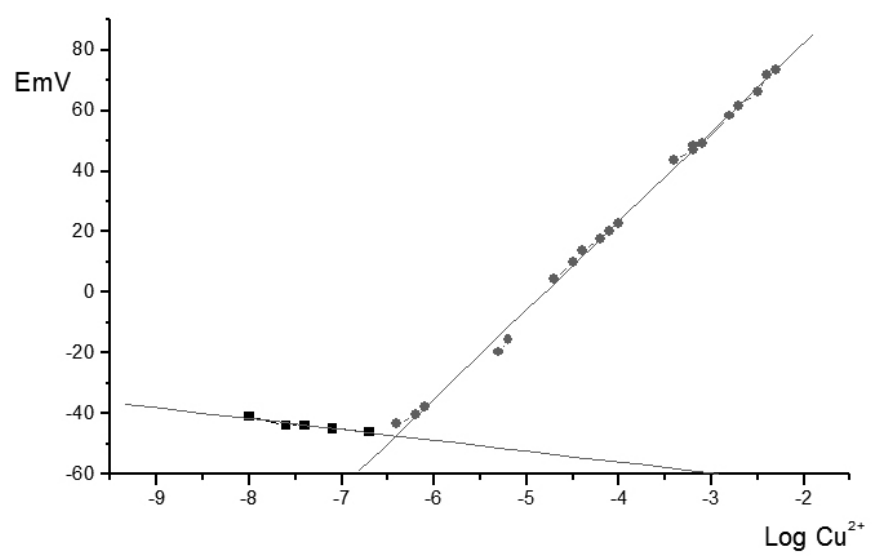

Figure 2: Calibration curve obtained by the method of additions for $\mathrm{Cu}^{2+}$ ISE with 1-furoil-3,3-diethylthiourea as neutral carrier.

Table 1. Calibration parameters for the constructed electrode.

\begin{tabular}{|c|c|}
\hline Parameter & $\mathbf{C u}^{\mathbf{2}}$ \\
\hline Slope $\mathbf{~ m V} / \mathbf{d e c a d e}$ & $29.34 \pm 0,6$ \\
\hline LPD $\mathbf{~ m o l} / \mathbf{d m}^{\mathbf{3}}$ & $3.84 \times 10^{-7}$ \\
\hline LLLR $\mathbf{~ m o l} / \mathbf{d m}^{\mathbf{3}}$ & $6.15 \times 10^{-7}$ \\
\hline Response Time & $20 \mathrm{~S}$ \\
\hline
\end{tabular}

\section{Response time}

The response time of the electrode was evaluated by immersing the electrode in a solution of primary ion $\left(10^{-2} \mathrm{~mol} / \mathrm{dm}^{3}\right)$ and reading the electrode potential to acquiere a stable value.

These response characteristics were repeatedly found throughout the lifetime of the electrode. The data presented in figure 3 were obtained with an electrode which was used under normal working conditions for 20 days.

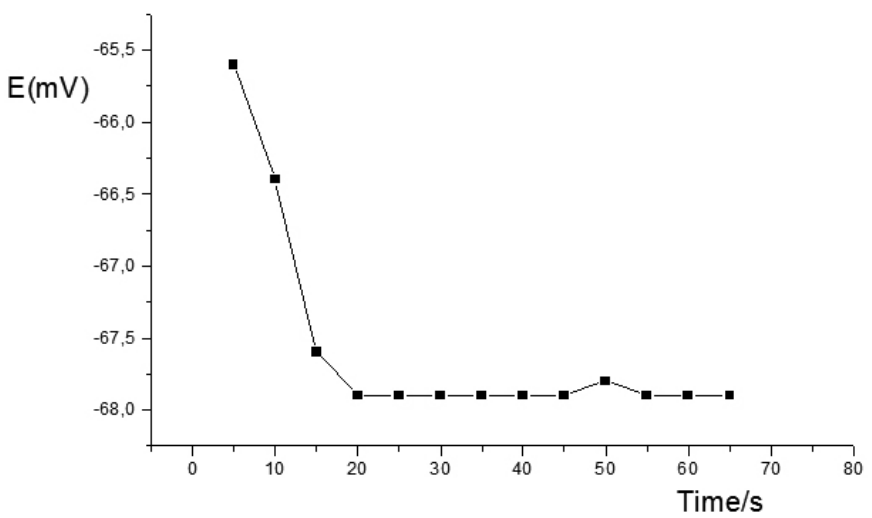

Figure 3: Potential stability as function of time for $\mathrm{Cu}^{2+}$ ISE for a concentration of primary ions of $10^{-2} \mathrm{~mol} / \mathrm{dm}^{3}$.

\section{Influence of $\mathrm{pH}$ on the response of the electrodes}

The effect of $\mathrm{pH}$ on the response of the electrodes was studied in this work by using the corresponding Reilley's diagram. An adjustment of $\mathrm{pH}$ was performed using dilute sodium hydroxide and nitric acid. The studied $\mathrm{pH}$ intervals for the constructed electrodes are shown in figure 4 . The experimental results showed that the variation of $\mathrm{pH}$ affected notably the electrode potential. It is seen from figure 4 that the electrode potential remains constant in $\mathrm{pH}$ intervals of 8.0 to 10.0

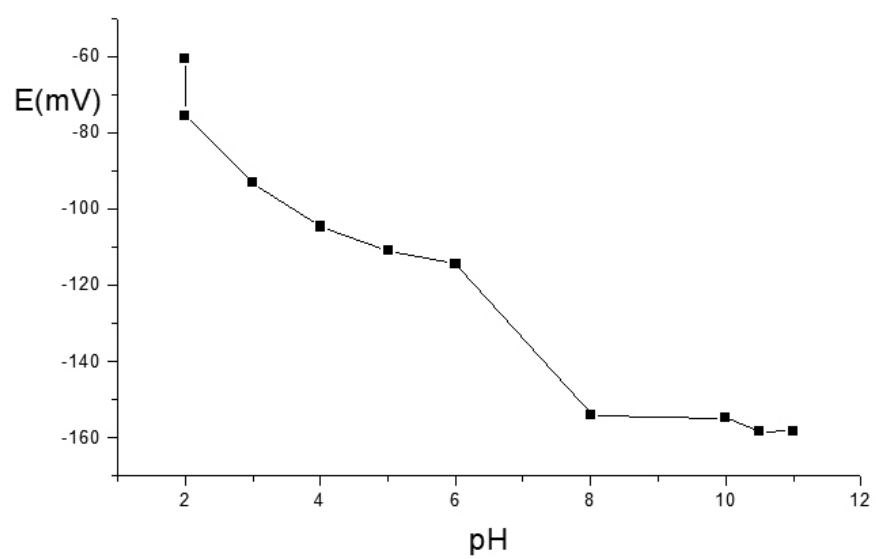

Figure 4: $\mathrm{pH}$ Dependence of the response of $\mathrm{Cu}^{2+}$ ion selective electrode for a concentration of primary ions of $10^{-2} \mathrm{~mol} / \mathrm{dm}^{3}$.

Study of the effect of interfering cations on the selectivity of the constructed ISE

The quantification of the selectivity of the constructed electrodes can be obtained by measuring the degree of the interference of different ions on the response of the electrode for cupper ion. This was done by determining the corresponding potentiometric selectivity coefficient ${ }^{15}\left(K_{A B}^{P o t}\right)$ in the presence of different interfering ions and the results are shown in table 2 together with the results obtained by sadeghi et. al. who used different Schiff base derivatives, 2,2-[4,4-diphenyl-methanebis(nitrilomethylidyne)]-bisphenol (L1) and 2,2-[4,4-diphenylsulfonebis (nitrilomethylidyne)]-bis(4-methyl phenol) (L6) as ionophors ${ }^{10}$.

Table 2: Selectivity determined for the ISE of liquid membrane by using the mixed solution method and in the presence of different interfering ions with a concentration of $10^{-2} \mathrm{~mol} / \mathrm{dm}^{3}$.

\begin{tabular}{|c|c|c|c|c|}
\hline $\begin{array}{c}\text { Interfering } \\
\text { ion }\end{array}$ & $K^{\text {Pot }}$ & $K_{A B}^{\text {Pot }}$ & $K_{A B \text { Ref. }{ }^{10}}^{\text {Pot }}$ & $\begin{array}{c}\text { Log } \\
K_{A B}^{\text {Pot }} \\
\text { Ref. }{ }^{10}\end{array}$ \\
\hline $\mathrm{K}^{+}$ & $\begin{array}{c}6.25 \\
\times 10^{-2}\end{array}$ & -1.2041 & $\begin{array}{c}\text { (L1) } 7.32 \times 10^{-4} \\
\text { (L6) } 2.22 \times 10^{-3}\end{array}$ & -3.4 \\
\hline $\mathrm{Na}^{+}$ & $\begin{array}{c}1.59 \\
\times 10^{-2}\end{array}$ & -1.2291 & $\begin{array}{c}\text { (L1) } 8.52 \times 10^{-4} \\
\text { (L6) } 9.10 \times 10^{-4}\end{array}$ & -4.2 \\
\hline $\mathrm{Zn}^{2+}$ & $\begin{array}{c}1.26 \\
\mathrm{x} 10^{-1}\end{array}$ & -0.8996 & $\begin{array}{l}\text { (L1) } 5.73 \times 10^{-3} \\
\text { (L6) } 4.90 \times 10^{-3}\end{array}$ & -4.0 \\
\hline
\end{tabular}

As can be seen from table 2, the $\mathrm{Zn}^{2+}$ presented major interference by the constructed ISE, where the interfering order was $\mathrm{Zn}^{2+}>\mathrm{Na}^{+}>\mathrm{K}^{+}$

The results obtained in this study were compared with those obtained by Sadeghi et. al. who used different Schiff base derivatives as ionofore ${ }^{10}$. The degree of interference observed for the electrodes constructed in this work was different compared to those electrodes constructed by using Schiff base derivatives $\mathrm{L} 1$ and $\mathrm{L} 6$, where much more interference was observed in the case of 1-furoil-3,3-diethylthiourea.

\section{CONCLUSIONS}

A new PVC membrane ion selective electrode for copper (II) was constructed by using 1-furoil-3,3-diethylthiourea as a neutral carrier (ionophore). The prepared $\mathrm{Cu}^{2+}$ ISEs showed almost the same Nernstian slope 
for $\mathrm{Cu}^{2+}$ with a practical detection limit (PDL) of $3.84 \times 10^{-7} \mathrm{~mol} / \mathrm{dm}^{3}$ and a response time of $20 \mathrm{~s}$. The $\mathrm{Cu}^{2+}$ ISE worked effectively in the $\mathrm{pH}$ range of $8.0-10.0$ and had a lifetime of 20 days.

\section{REFERENCES}

1.- H. Scheinberg, A. G. Morell, Inorganic Biochemistry, Elsevier, Amsterdam 1973

2.- A. R. Fakhari, T. A. Raji, H. H. Naeimi, Sens. Actuators B: Chem., 104, 317 (2005)

3.- S. J. Park, O. J. Shon, J. A. Rim, J. K. Lee, J. S. Kim, H. Nam, H. Kim, Talanta, 55(2), 297 (2001)

4.- M. H. Mashhadizadeh, A. Mostafavi, R. Razavi, M. Shamsipur, Sens. Actuators B: Chemical, 86(2-3), 222 (2002)

5.- S. Yoshimoto, H. Mukai, T. Kitano, Y. Sohrin, Anal. Chim. Acta, 494, 207 (2003)

6.- M. Shamsipur, A. Avanes, M. Javanbakht, M. R. Ganjali, H. Sharghi, Anal. Sci., 18, 875 (2002)
7.- $\quad$ M. Shamsipur, M. Javanbakht, M. F. Mousavi, M. R. Ganjali, V. Lippolis, A. Garau, L. Tei, Talanta, 55, 1047 (2001)

8.- E. Bakker, P. Buhlmann, E. Pretsch, Talanta, 63, 3 (2004)

9.- E. Bakker, P. Buhlmann, E. Pretsch, Electroanalysis, 11(13), 915 (1999)

10.- S. Sadeghi, M. Eslahi, M. A. Naseri, H. Naeimi, H. Sharghi, A. Shameli. Electroanalysis, 15(15-16), 1327 (2003)

11.- M.B. Gholivand, M. Rahimi-Nasrabadi, M.R. Ganjali, M. SalavatiNiasari, Talanta, 73, 553 (2007)

12.- Shin-ichi Wakida, Nagahisa Sato, Keiitsu Saito, Sens. and Actuators B: Chemical, 130187 (2008)

13.- M. A. Arada, L. Pérez-Marín, J. Calvo, M. Yazdani-Pedram, Sens. Actuators B: Chemical, 89, 262 (2003)

14.- M. de los Á. Arada Pérez, M. Yazdani-Pedram. J. Chil. Chem. Soc. 49 (3), 227 (2004)

15.- IUPAC "Compendium of Analytical Nomenclature Oxford Pergamon Press", 168-173 (1978) 